\title{
Anti-acetylcholinesterase, antidiabetic, anti-inflammatory, antityrosinase and antixanthine oxidase activities of Moroccan propolis
}

\author{
Soukaina El-Guendouz, ${ }^{1,2}$ Smail Aazza, ${ }^{1,2}$ Badiaâ Lyoussi, ${ }^{1}$ Maria D. Antunes, ${ }^{2}$ Maria L. Faleiro ${ }^{3}$ \& \\ Maria G. Miguel ${ }^{2 *}$ \\ 1 Laboratory of Physiology, Pharmacology and Environmental Health, Faculty of Sciences Dhar El Mehraz, University Sidi Mohamed Ben \\ Abdallah, BP 1796 Atlas, Fez 30 000, Morocco \\ 2 Faculdade de Ciências e Tecnologia, MeditBio, Universidade do Algarve, Campus de Gambelas, 8005-139 Faro, Portugal \\ 3 Faculdade de Ciências e Tecnologia, CBMR, Universidade do Algarve, Edf. 8, Campus de Gambelas, 8005-139 Faro, Portugal
}

(Received 22 December 2015; Accepted in revised form 3 April 2016)

\begin{abstract}
Summary Biological properties of Moroccan propolis have been scarcely studied. In the present work, the total phenols and flavonoids from 21 samples of propolis collected in different places of Morocco or 3 supplied in the market were determined, as well as the in vitro capacity for inhibiting the activities of acetylcholinesterase, $\alpha$-glucosidase, $\alpha$-amylase, lipoxygenase, tyrosinase, xanthine oxidase and hyaluronidase. The results showed that samples 1 (region Fez-Boulemane, Sefrou city) $\left(\mathrm{IC}_{50}=0.065,0.006,0.020,0.050\right.$, $\left.0.014 \mathrm{mg} \mathrm{mL}^{-1}\right)$ and 23 (marketed) $\left(\mathrm{IC}_{50}=0.018,0.002,0.046,0.037,0.008 \mathrm{mg} \mathrm{mL}^{-1}\right)$ had the best in vitro capacity for inhibiting the $\alpha$-amylase, $\alpha$-glucosidase, lipoxygenase, tyrosinase and xanthine oxidase activities, respectively. A negative correlation between $\mathrm{IC}_{50}$ values and concentration of phenols, flavones and flavanones was found. These activities corresponded to the generally higher amounts of phenols and flavonoids. In the same region, propolis samples have dissimilar phenol content and enzyme inhibitory activities.
\end{abstract}

Keywords $\quad \alpha$-amylase, $\alpha$-glucosidase, hyaluronidase, hydroethanolic extracts, lipoxygenase, propolis.

\section{Introduction}

Propolis is a plant product-resinous mixture with a broad spectrum of biological properties, collected by the Apis mellifera bee from the bud and exudates of various plants and transformed in the presence of bee enzymes (Miguel et al., 2014a,b). The wide application of propolis in modern medicine and the increasing demand for it, due to its health benefits and use in cosmetic and food products, have drawn growing attention to its chemical composition, which is susceptible to the geographical location, collection site, botanical origin (Salatino et al., 2011), bee species (Silici \& Kutluca, 2005) and the availability of water and climate (Boufadi et al., 2014). Flavonoids, phenylpropanoids, terpenoids, stilbenes, lignans, coumarins and their prenylated derivatives, alkaloids and iridoids are some groups of compounds identified in propolis worldwide. This chemical diversity is related to the

*Correspondent: E-mail: mgmiguel@ualg.pt bioactivity and potential uses of this product (Huang et al., 2014).

The biological properties attributed to the propolis of different parts of the world have been the target of studies, and very recently, Silva-Carvalho et al. (2015) compiled the recent published information about antibacterial and antifungal, antiviral, anti-inflammatory, antioxidant, immunomodulatory and antitumor activities of propolis.

Alzheimer's disease is a progressive, neurodegenerative disease that is clinically characterised by a progressive loss of cognitive abilities. The pathophysiology of that disease involves defective beta-amyloid protein metabolism, abnormalities of glutamatergic, adrenergic, serotonergic and dopaminergic neurotransmission and the potential involvement of inflammatory, oxidative and hormonal pathways (Kang et al., 2005; Chen et al., 2008). For the treatment of Alzheimer's disease, acetylcholinesterase (AChE) inhibitors are included, which increase the availability of acetylcholine at cholinergic synapses, 
although the modest benefits were obtained (Chen et al., 2008). Some natural products of plant origin have revealed to be effective acetylcholinesterase inhibitors - of them some were used as medicines, such as some alkaloids (galantamine). Other groups of compounds have been also checked and some flavonoids have also revealed the ability for inhibiting this enzyme (Scotti \& Scotti, 2015). Only very few works regarding the capacity of propolis extracts to inhibit acetylcholinesterase have been published (Chen et al., 2008; Miguel et al., 2014b).

Postprandial hyperglycaemia plays an important role in the development of type 2 diabetes mellitus, and one strategy used to stabilise postprandial plasma glucose is the utilisation of specific enzyme inhibitors, such as $\alpha$-glucosidase and pancreas $\alpha$-amylase inhibitors (Murai et al., 2002). Natural bioactive compounds with the capacity to delay the glucose absorption by the inhibition of $\alpha$-glucosidase or $\alpha$-amylase activities and consequently to moderate the excess postprandial blood glucose level have been searched, including those present in the propolis from different geographical origins: China (Zhang et al., 2015), Morocco (Popova et al., 2015) and Brazil (Matsui et al., 2004).

The inhibition of lipoxygenase has been considered as an indicator of anti-inflammatory and antioxidant activities. 5-Lipoxygenase is the key enzyme of leukotriene biosynthesis, and it has been the target for many inhibitors for trying to find potential drugs for combating a variety of inflammation- and hypersensitivitybased human diseases including asthma, arthritis, bowel diseases such as ulcerative colitis and Crohn's disease and circulatory disorders such as shock and myocardial ischaemia (Sailer et al., 1996).

Propolis (Miguel et al., 2014b) and particularly some components (e. g. caffeic acid phenethyl ester) have been reported as lipoxygenase inhibitors with antioxidant properties (Sud'ina et al., 1993; Mirzoeva \& Calder, 1996; Touaibia \& Guay, 2011).

Hyaluronidase is an enzyme that depolymerises the polysaccharide hyaluronic acid in the extracellular matrix of connective tissue, and it is involved in allergic reactions and inflammation (Moon et al., 2009). Hyaluronidase inhibitors may have therefore anti-allergic and anti-inflammatory properties. Inhibition of hyaluronidase by propolis from diverse geographical origins such as Portugal (Silva et al., 2012) and China and Brazil (Miyataka et al., 1997; Park \& Ikegaki, 1998) has been reported, and therefore, propolis is considered as a potential anti-inflammatory natural product.

Tyrosinase (monophenol or $o$-diphenol, oxygen oxidoreductase), also known as polyphenol oxidase (PPO), is a copper-containing monooxygenase. This enzyme is a key in melanin biosynthesis, which involves in the colour formation of mammalian hair and skin and prevents the skin from damage by ultraviolet (Nerya et al., 2003; Dong et al., 2014). Propolis from diverse origins (Australia, Brazil, China, Hungary, Japan, Ukraine and Uruguay) has been described to inhibit the tyrosinase activity (Tazawa et al., 2001).

The enzyme xanthine oxidase catalyses the oxidation of hypoxanthine and xanthine to uric acid. Overproduction of uric acid, termed hyperuricaemia, is the underlying cause of gout. During the reoxidation of xanthine oxidase, molecular oxygen acts as an electron acceptor, producing superoxide radical and hydrogen peroxide (Cos et al., 1998). During this process, beyond the production of uric acid, there is also the production of reactive oxygen species that contribute to the oxidative stress which is involved in several pathological processes such as inflammation, atherosclerosis, cancer, ageing, among other ones (Cos et al., 1998).

Propolis extracts and their components have the ability to inhibit xanthine oxidase, either in vitro or in vivo systems, which may be considered as potential agent against gout and oxidation (the production of superoxide radical and hydrogen peroxide is hampered) (Ilhan et al., 2004; Yoshizumi et al., 2005; Armutcu et al., 2015).

Only very few works have focused on Moroccan propolis. One of the few studies concerning propolis extracts from this country reported in vitro and in vivo anticancer properties (Ait Mouse et al., 2012), whereas antioxidant, anti-inflammatory (the inhibition of lipoxygenase activity) and anti-acetylcholinesterase activities of fourteen propolis samples from diverse regions of Morocco were evaluated by Miguel et al. (2014b) and $\alpha$-glucosidase and $\alpha$-amylase inhibitory activities were reported by Popova et al. (2015) from the propolis collected in five diverse locations of that country.

The main goal of the present work was to evaluate the inhibitory activities of 21 propolis samples of diverse geographical origins of Morocco on acetylcholinesterase, lipoxygenase, $\alpha$-glucosidase and $\alpha$-amylase activities, previously studied but with fewer number of propolis samples (Miguel et al., 2014b; Popova et al., 2015). At the same time, other enzyme inhibitory activities, such as xanthine oxidase and hyaluronidase, enzymes also involved in inflammatory processes, were evaluated, as well as the inhibitory activity of tyrosinase by the same samples. This work may contribute to ascertain the importance or not of the harvesting places on the enzyme inhibitory activities. In addition, three samples purchased from the market were also the target of study, due to the increasing demand and sell of propolis by Moroccan people. 


\section{Material and methods}

\section{Hydroalcoholic extract of propolis}

Twenty-four propolis samples were provided by diverse Moroccan beekeepers or purchased from the market. The harvesting places and their coordinates, climate data as well as the surrounding plants of the beehives are given in Table S1.

Extracts were obtained as reported by Miguel et al. (2014b) with slight modifications. Briefly, one gram of propolis was chopped into small pieces and extracted by maceration using $30 \mathrm{~mL}$ of $70 \%$ ethanol and maintained for 1 week at $37{ }^{\circ} \mathrm{C}$ under agitation $(200 \mathrm{rpm})$. The resulting solution was filtered under vacuum. For the successive analyses, a clear solution, without further purification, was used to prepare serial dilutions with the concentrations of $33.33,16.66,8.33,4.17$, $2.08,1.04,0.52$ and $0.26 \mathrm{mg} \mathrm{mL}^{-1}$.

\section{Chemicals}

Acetylthiocholine iodide (ATCI), AChE (type VI-S) from the electric eel Electrophorus electricus, 5, 5' dithiobis(2-nitrobenzoic acid) (DTNB), hyaluronidase from bovine testes, sodium tetraborate, alpha-amylase, alpha-glucosidase, 5-lipoxygenase from soya bean, linoleic acid, mushroom tyrosinase, L-DOPA, xanthine oxidase, xanthine and methanol were purchased from Sigma-Aldrich (St. Louis, MO, USA). p-Nitrophenyl$\beta$-D-glucopyranoside (PNPG), boric acid, ascorbic acid, Tris- $\mathrm{HCl}$ and hydrochloric acid $(\mathrm{HCl})$ were purchased from Merck, Darmstadt, Germany. Starch, potassium iodide, iodine and $\mathrm{Na}_{2} \mathrm{CO}_{3}$ were purchased from Riedel de Haen (Seelze, Germany), Riedel-deHaën Laboratory chemicals, Germany. Calcium chloride, Folin-Ciocalteu's phenol reagent and $\mathrm{AlCl}_{3}$ were purchased from Panreac Química, Montcada i Reixac, Barcelona, Spain. Acetic acid, PDMAB ( $p$ dimethylaminobenzaldehyde), potassium dihydrogen phosphate $\left(\mathrm{KH}_{2} \mathrm{PO}_{4}\right)$, dipotassium hydrogen phosphate $\left(\mathrm{K}_{2} \mathrm{HPO}_{4}\right)$, sodium dihydrogen phosphate $\left(\mathrm{NaH}_{2} \mathrm{PO}_{4}\right)$ and disodium hydrogen phosphate $\left(\mathrm{Na}_{2} \mathrm{HPO}_{4}\right)$ were purchased from VWR (Leuven, Belgium). Ferulic Acid, DNP (2,4-dinitrophenylhydrazine), quercetin, $\mathrm{H}_{2} \mathrm{SO}_{4}$ and $\mathrm{KOH}$ and eriodictyol were purchased from Fluka Biochemika (Sigma-Aldrich, Steinheim, Germany).

\section{Total phenol content}

The total polyphenol content in propolis samples was determined using the method of Gülcin et al. (2005). Hydroalcoholic extracts $(25 \mu \mathrm{L})$ were mixed with $125 \mu \mathrm{L}$ of Folin-Ciocalteu's phenol reagent $(0.2 \mathrm{~N})$ and $100 \mu \mathrm{L}$ of $7.5 \% \mathrm{Na}_{2} \mathrm{CO}_{3}$, and the absorbance was measured at $765 \mathrm{~nm}$ after $2 \mathrm{~h}$ of incubation at room temperature. The total polyphenol content was expressed as $\mathrm{mg}$ ferulic acid equivalents per $\mathrm{mL}(\mathrm{mg}$ FAE $\mathrm{mL}^{-1}$ ) using a calibration curve.

\section{Flavones and flavonol content}

The amounts of flavones and flavonols in the extracts were determined according to the method of Miguel et al. (2010) with a minor modification. An amount of $100 \mu \mathrm{L}$ of $\mathrm{AlCl}_{3}(20 \%)$ was added to $100 \mu \mathrm{L}$ of extract, and after $1 \mathrm{~h}$ at room temperature, the absorbance was measured at $420 \mathrm{~nm}$. Total flavone and the flavonol contents were calculated as $\mathrm{mg}$ quercetin equivalents per $\mathrm{mL}\left(\mathrm{mg} \mathrm{QE} \mathrm{mL}^{-1}\right)$ using a calibration curve.

\section{Flavanone and dihydroflavonol contents}

The quantification of total flavanones and dihydroflavonols was performed as described by Popova et al. (2004) with slight modifications. Briefly, $75 \mu \mathrm{L}$ of sample and $2 \mathrm{~mL}$ of DNP (2,4-dinitrophenylhydrazine) solution (1 g DNP in $2 \mathrm{~mL} \mathrm{96 \%} \mathrm{sulphuric} \mathrm{acid,}$ diluted to $100 \mathrm{~mL}$ with methanol) were heated at $50{ }^{\circ} \mathrm{C}$ for $50 \mathrm{~min}$. After cooling at room temperature, the mixture was diluted to $10 \mathrm{~mL}$ with $10 \% \mathrm{KOH}$ in methanol $(\mathrm{w} / \mathrm{v})$. A sample $(1 \mathrm{~mL})$ of the resulting solution was added to $10 \mathrm{~mL}$ methanol and diluted to $50 \mathrm{~mL}$ with methanol. The absorbance was measured at $486 \mathrm{~nm}$.

\section{Inhibition of acetylcholinesterase}

Acetylcholinesterase degrades the substrate acetylcholine into acetic acid and thiocholine, which interacts with 5,5'-dithiobis-2-nitrobenzoic acid (DTNB). Accumulation of 5-thio-2-nitrobenzoic acid was measured at $405 \mathrm{~nm}$. The acetylcholinesterase inhibition assay was adapted from the method of Mata et al. (2007). About $25 \mu \mathrm{L}$ of sample, $425 \mu \mathrm{L}$ of Tris- $\mathrm{HCl}$ buffer $(0.1 \mathrm{M}, \mathrm{pH} 8)$ and $25 \mu \mathrm{L}$ of enzyme (0.28 $\left.\mathrm{U} \mathrm{mL}^{-1}\right)$ were added, and then the mixture was agitated and incubated for $15 \mathrm{~min}$ at room temperature. After this period, $75 \mu \mathrm{L}$ of substrate $(0.005 \mathrm{~g}$ of iodine acetylcholine in $10 \mathrm{~mL}$ of buffer) and $475 \mu \mathrm{L}$ of 5,5'-dithiobis-2-nitrobenzoic acid (DTNB) (0.059 $\mathrm{g}$ in $50 \mathrm{~mL}$ of buffer) were then added. The absorbance of sample $\left(\mathrm{Abs}_{\text {sample }}\right)$ was read after $30 \mathrm{~min}$ and compared with the absorbance of the control $\left(\mathrm{Abs}_{\text {cont }}\right)$ in which the sample was replaced by buffer. Inhibition percentage of enzyme was calculated as follows: $\left[\left(\mathrm{Abs}_{\text {cont }}-\mathrm{Abs}_{\text {sample }}\right) / \mathrm{Abs}_{\text {cont }}\right] \times 100$. The analyses were carried out in triplicate. The inhibition 
percentage of enzyme was plotted against propolis extract concentration $(\mathrm{w} / \mathrm{v})$, and $\mathrm{IC}_{50}$ values were determined (the concentration of propolis extract able to inhibit $50 \%$ of acetylcholinesterase).

\section{Inhibition of $\alpha$-amylase and $\alpha$-glucosidase}

$\alpha$-Amylase inhibition assay

$\alpha$-Amylase inhibition assay was carried out by a modified starch iodine (Uddin et al., 2014). The total assay mixture consisting of $100 \mu \mathrm{L}$ sodium phosphate buffer $(0.02 \mathrm{M}, \mathrm{pH} 6.9$ containing $6 \mathrm{~mm}$ sodium chloride), $50 \mu \mathrm{L}$ of $\alpha$-amylase (0.02 units) and propolis was incubated at $37^{\circ} \mathrm{C}$ for $10 \mathrm{~min}$. After the incubation, $200 \mu \mathrm{L}$ of soluble starch $(1 \%, \mathrm{w} / \mathrm{v})$ was added to each test tube and the mixture was reincubated for $20 \mathrm{~min}$ at $37^{\circ} \mathrm{C}$. About $300 \mu \mathrm{L}$ of $10 \% \mathrm{HCl}$ was added to stop the enzymatic reaction, followed by the addition of $300 \mu \mathrm{L}$ of iodine reagent $\left(5 \mathrm{~mm} \mathrm{I}_{2}\right.$ and $\left.5 \mathrm{~mm} \mathrm{KI}\right)$, and after that, $8 \mathrm{~mL}$ of distilled water was added. The absorbance was read at $620 \mathrm{~nm}$. Sample, substrate and blank were undertaken under the same conditions. Each experiment was done in triplicate. The inhibition percentage of the enzyme was calculated using the following formula:

$\%$ of $\alpha$-amylase inhibition:

$$
\left[1-\frac{\left[\left(A_{\text {control }}^{-}\right)-\left(A_{\text {control }}^{+}\right)\right]-\left(A_{\text {sample }}\right)}{\left(A_{\text {control }}^{-}\right)-\left(A_{\text {control }}^{+}\right)}\right] \times 100
$$

where $A_{\text {control }}^{-}$denotes the absorbance of $100 \%$ enzyme activity (ethanol $70 \%$ with enzyme), $A_{\text {control }}^{+}$denotes the absorbance of $0 \%$ enzyme activity (ethanol $70 \%$ without enzyme), and $A_{\text {sample }}$ denotes the absorbance of sample. And then, the $\mathrm{IC}_{50}$ values were compared.

\section{$\alpha$-Glucosidase inhibition assay}

The yeast $\alpha$-glucosidase inhibitory activity of the 24 propolis samples was determined by a modified version of the method described by Popova et al. (2015). Briefly, a mixture of $25 \mu \mathrm{L}$ of different concentrations of the samples, $30 \mu \mathrm{L}$ of yeast $\alpha$-glucosidase (2.4 $\mathrm{U} \mathrm{mL}^{-1}$ ) and $100 \mathrm{~mm}$ phosphate buffer ( $\mathrm{pH}$ 6.8) was incubated in 96-well plates at room temperature for $10 \mathrm{~min}$. After pre-incubation, $100 \mu \mathrm{L}$ of $0.5 \mathrm{~mm}$ nitrophenyl- $\beta$-D-glucopyranoside (PNPG) solution in phosphate buffer was added to each well. The reaction mixtures were incubated at $37{ }^{\circ} \mathrm{C}$ for $30 \mathrm{~min}$, and then $80 \mu \mathrm{L}$ of sodium carbonate solution $(0.4 \mathrm{~mm})$ was added to stop the reaction. The absorbance was recorded with a microplate reader at $405 \mathrm{~nm}$. The control had $25 \mu \mathrm{L}$ of $70 \%$ ethanol instead of test samples. The inhibition percentage of the enzyme was calculated, and the $\mathrm{IC}_{50}$ values were compared. The analyses were carried out in triplicate.

\section{Inhibition of lipoxygenase}

The inhibition of lipoxygenase was carried out as previously reported by Frum \& Viljoen (2006). The reaction was initiated by the addition of $5 \mu \mathrm{L}$ 5-lipoxygenase solution $(0.054 \mathrm{~g}$ in $1 \mathrm{~mL}$ borate buffer $0.005 \%$, Tween $0.1 \mathrm{M}, \mathrm{pH}$ 9) to $937 \mu \mathrm{L}$ borate buffer, $10 \mu \mathrm{L}$ sample and $50 \mu \mathrm{L}$ linoleic acid $(0.001 \mathrm{M})$. The enzymatic reactions were performed in the absence or in the presence of propolis extracts and their kinetics were compared. The inhibition percentage of the enzyme was calculated, and the $\mathrm{IC}_{50}$ values were compared. The analyses were carried out in triplicate.

\section{Inhibition of tyrosinase}

The inhibitory action of propolis on tyrosinase was evaluated as previously described by El-Hady et al. (2014), but with the slight modifications. In short, $140 \mu \mathrm{L}$ phosphate buffer (50 mM, pH 6.5), $25 \mu \mathrm{L}$ of sample and $60 \mu \mathrm{L}$ of mushroom tyrosinase solution $\left(100 \mathrm{U} \mathrm{mL}^{-1}\right)$ were added to a 96-well microplate. The assay mixture was incubated at $25^{\circ} \mathrm{C}$ for $40 \mathrm{~min}$. Following incubation, $60 \mu \mathrm{L}$ of $5 \mathrm{~mm}$ L-DOPA solution was added and the amount of dopachrome produced in the reaction mixture was determined spectrophotometrically at $492 \mathrm{~nm}$ in a microplate reader. The percentage of inhibition of tyrosinase activity was calculated and the $\mathrm{IC}_{50}$ value was determined.

\section{Inhibition of xanthine oxidase}

Xanthine oxidase activity was determined by measuring the formation of uric acid from xanthine. Xanthine oxidase inhibiting activity was conveniently measured with a modified assay according to Umamaheswari et al. (2013). The assay mixture consisted of $100 \mu \mathrm{L}$ of the sample, $350 \mu \mathrm{L}$ of phosphate buffer $(\mathrm{pH} 7.5$, $50 \mathrm{~mm}$ ) and $45 \mu \mathrm{L}$ of xanthine oxidase enzyme solution (0.4 units $\mathrm{mL}^{-1}$ in phosphate buffer, $\mathrm{pH} 7.5$ ), which was prepared immediately before use. After preincubation at room temperature for $15 \mathrm{~min}$, the reaction was initiated by the addition of $330 \mu \mathrm{L}$ of $0.150 \mathrm{~mm}$ xanthine solution (substrate). The assay mixture was incubated for $30 \mathrm{~min}$. The reaction was stopped by adding $100 \mu \mathrm{L}$ of $1 \mathrm{M} \mathrm{HCl}$, and the absorbance was measured at $290 \mathrm{~nm}$ using an UV/VIS spectrophotometer. The assay was done in triplicate, and the $\mathrm{IC}_{50}$ values were calculated from the percentage of inhibition.

\section{Inhibition of hyaluronidase}

Hyaluronidase inhibition was determined by measuring the amount of $N$-acetylglucosamine separated from 
sodium hyaluronate as described by Sahasrabudhe \& Deodhar (2010). Bovine hyaluronidase solution $(150 \mu \mathrm{L})\left(7900\right.$ units $\left.\mathrm{mL}^{-1}\right)$ dissolved in acetate buffer (pH 3.6) was mixed with $25 \mu \mathrm{L}$ of propolis extracts and incubated for $30 \mathrm{~min}$ at $37^{\circ} \mathrm{C}$. After $30 \mathrm{~min}$, $50 \mu \mathrm{L}$ of calcium chloride $(12.5 \mathrm{~mm})$ was added to the reaction mixture and again incubated for $30 \mathrm{~min}$ at $37{ }^{\circ} \mathrm{C}$. After this period, $250 \mu \mathrm{L}$ sodium hyaluronate $\left(1.2 \mathrm{mg} \mathrm{mL}^{-1}\right)$ was added and again incubated at $37{ }^{\circ} \mathrm{C}$ for $1 \mathrm{~h} 30 \mathrm{~min}$. After incubation, $50 \mu \mathrm{L}$ of $0.4 \mathrm{M}$ sodium hydroxide and $100 \mu \mathrm{L}$ of $0.6 \mathrm{~m}$ sodium borate were added to the reaction mixture and incubated in the boiling water bath for 3 min. After cooling in ice, $1.5 \mathrm{~mL}$ of PDMAB ( $p$-dimethylaminobenzaldehyde) solution (4 g PDMAB dissolved in $50 \mathrm{~mL}$ of $10 \mathrm{M} \mathrm{HCL}$ and $350 \mathrm{~mL}$ of glacial acetic acid) was added to the reaction mixture. The absorbance was measured at $585 \mathrm{~nm}$. The assay was done in triplicate.

\section{Statistical analysis}

Statistical analysis was performed with the Statistical Package for the Social Sciences (SPSS) 23.0 software (SPSS Inc., Chicago, IL, USA). Statistical comparisons were made with one-way analysis of variance followed by Tukey's multiple comparisons. The level of significance was set at $P<0.05$. Correlations between phenol and flavonoid contents and enzyme inhibitory activities were achieved by Spearman's correlation coefficient $(r)$ at a significance level of $95 \%$. Hierarchical cluster analysis was used to investigate the similarities and dissimilarities between the 24 propolis samples with respect to the total phenols, flavones and flavonols, flavanones and dihydroflavonols content and the capacity to inhibit xanthine oxidase and $\alpha$-amylase activities. In 9 samples, due to its low inhibitory activity on $\alpha$-glucosidase, lipoxygenase, acetylcholinesterase and tyrosinase, the $\mathrm{IC}_{50}$ values were impossible to determine in some assays. In this case, only 15 samples were submitted to hierarchical cluster analysis, to investigate the similarities and dissimilarities between the 15 propolis samples with respect to the total phenols, flavones and flavonols, flavanones and dihydroflavonols contents and the capacity for inhibiting those enzymes. In any case, for the classification purposes, the Ward's minimum variance method was used; the squared Euclidean distance was used as the dissimilarity measure for Ward's method.

\section{Results and discussion}

\section{Phenols and flavonoids}

The concentrations of total phenols, flavones and flavonols, and flavanones and dihydroflavonols found for propolis samples collected in several places of Morocco are presented in Table 1. The results reveal a great variability in concentrations of all groups of phenols. Concerning total phenols, the concentrations ranged from $0.236 \mathrm{mg}$, in sample 24 , to $8.846 \mathrm{mg}$ FAE $\mathrm{mL}^{-1}$ in sample 17. Sample $23(8.827 \mathrm{mg}$ FAE $\mathrm{mL}^{-1}$ ) had a concentration similar to that of sample 17. Total phenol concentrations of samples 1 and 10 were 6.861 and $4.802 \mathrm{mg} \mathrm{FAE} \mathrm{mL}{ }^{-1}$, respectively. The amounts of flavones and flavonols were always superior to those of flavanones and dihydroflavonols (Table 1). As reported for total phenols, the concentrations of flavones and flavonols were higher in the sample $17\left(4.320 \mathrm{mg} \mathrm{QE} \mathrm{mL}^{-1}\right)$, immediately followed by the samples 23 (2.699 $\left.\mathrm{mg} \mathrm{QE} \mathrm{mL}^{-1}\right)$ and $1 \quad\left(1.784 \mathrm{mg} \quad \mathrm{QE} \mathrm{mL} \mathrm{mL}^{-1}\right)$. Concerning dihydroflavonols, the sample 23 had the highest amount of this group of compounds $\left(0.532 \mathrm{mg} \mathrm{EE} \mathrm{mL}{ }^{-1}\right)$ and not sample 17, as found for total phenols and flavones and flavonols, immediately followed by samples 1 (0.257 $\mathrm{mg} \mathrm{EE} \mathrm{mL}^{-1}$ ) and 17 (0.222 $\mathrm{mg} \mathrm{EE} \mathrm{mL}^{-1}$ ).

The highest concentrations of total phenols and flavonoids found in the hydroethanolic extracts of Moroccan propolis in the present work are within the

Table 1 Concentration of total phenols, flavonols, flavones, flavanones and dihydroflavonols in propolis extracts

\begin{tabular}{|c|c|c|c|}
\hline Samples & $\begin{array}{l}\text { Phenols } \\
\text { (mg FAE } \mathrm{mL}^{-1} \\
\text { extract) }\end{array}$ & $\begin{array}{l}\text { Flavonoids } \\
\text { (mg QE } \mathrm{mL}^{-1} \\
\text { extract) }\end{array}$ & $\begin{array}{l}\text { Dihydroflavones } \\
\text { (mg (EE } \mathrm{mL}^{-1} \\
\text { extract) }\end{array}$ \\
\hline 1 & $6.861 \pm 0.016^{b}$ & $1.784 \pm 0.012^{\mathrm{c}}$ & $0.257 \pm 0.001^{b}$ \\
\hline 2 & $0.564 \pm 0.016^{1}$ & $0.097 \pm 0.012^{\mathrm{jkl}}$ & $0.047 \pm 0.001^{m}$ \\
\hline 3 & $1.101 \pm 0.016^{i}$ & $0.353 \pm 0.012^{\mathrm{g}}$ & $0.092 \pm 0.001^{\mathrm{h}}$ \\
\hline 4 & $0.436 \pm 0.016^{\mathrm{m}}$ & $0.088 \pm 0.012^{\mathrm{kl}}$ & $0.050 \pm 0.001^{m}$ \\
\hline 5 & $0.732 \pm 0.016^{k}$ & $0.143 \pm 0.012^{i j}$ & $0.070 \pm 0.001^{k}$ \\
\hline 6 & $0.465 \pm 0.016^{\mathrm{m}}$ & $0.107 \pm 0.012^{\mathrm{jk}}$ & $0.060 \pm 0.001^{1}$ \\
\hline 7 & $0.260 \pm 0.016^{\text {no }}$ & $0.028 \pm 0.012^{\mathrm{mno}}$ & $0.031 \pm 0.001^{\circ}$ \\
\hline 8 & $1.921 \pm 0.016^{f}$ & $0.402 \pm 0.012^{f}$ & $0.084 \pm 0.001^{i}$ \\
\hline 9 & $0.443 \pm 0.016^{\mathrm{m}}$ & $0.057 \pm 0.012^{1 \mathrm{mn}}$ & $0.057 \pm 0.001^{\prime}$ \\
\hline 10 & $4.802 \pm 0.016^{c}$ & $0.781 \pm 0.012^{\mathrm{d}}$ & $0.168 \pm 0.001^{\mathrm{e}}$ \\
\hline 11 & $0.699 \pm 0.016^{\mathrm{k}}$ & $0.067 \pm 0.012^{\mathrm{klm}}$ & $0.060 \pm 0.001^{1}$ \\
\hline 12 & $0.318 \pm 0.016^{n}$ & $0.006 \pm 0.012^{\circ}$ & $0.038 \pm 0.001^{n}$ \\
\hline 13 & $1.307 \pm 0.016^{h}$ & $0.186 \pm 0.012^{i}$ & $0.071 \pm 0.001^{\mathrm{jk}}$ \\
\hline 14 & $2.113 \pm 0.016^{\mathrm{e}}$ & $0.409 \pm 0.012^{f}$ & $0.139 \pm 0.001^{f}$ \\
\hline 15 & $1.929 \pm 0.016^{f}$ & $0.331 \pm 0.012^{h}$ & $0.176 \pm 0.001^{d}$ \\
\hline 16 & $1.787 \pm 0.016^{\mathrm{g}}$ & $0.297 \pm 0.012^{h}$ & $0.0142 \pm 0.001^{f}$ \\
\hline 17 & $8.864 \pm 0.016^{\mathrm{a}}$ & $4.320 \pm 0.012^{\mathrm{a}}$ & $0.222 \pm 0.001^{\mathrm{c}}$ \\
\hline 18 & $0.802 \pm 0.016^{\mathrm{j}}$ & $0.0136 \pm 0.012^{\mathrm{j}}$ & $0.058 \pm 0.001^{\prime}$ \\
\hline 19 & $0.477 \pm 0.016^{\mathrm{m}}$ & $0.069 \pm 0.012^{\mathrm{klm}}$ & $0.074 \pm 0.001^{k}$ \\
\hline 20 & $2.429 \pm 0.016^{d}$ & $0.604 \pm 0.012^{\mathrm{e}}$ & $0.109 \pm 0.001^{g}$ \\
\hline 21 & $0.261 \pm 0.016^{\text {no }}$ & $0.020 \pm 0.012^{\mathrm{mn}}$ & $0.077 \pm 0.001^{j}$ \\
\hline 22 & $1.892 \pm 0.016^{f}$ & $0.0427 \pm 0.012^{f}$ & $0.138 \pm 0.001^{f}$ \\
\hline 23 & $8.827 \pm 0.016^{\mathrm{a}}$ & $2.699 \pm 0.012^{b}$ & $0.532 \pm 0.001^{\mathrm{a}}$ \\
\hline 24 & $0.039 \pm 0.016^{\circ}$ & $0.039 \pm 0.012^{\mathrm{mno}}$ & $0.058 \pm 0.001^{1}$ \\
\hline
\end{tabular}

Values with the same letter are not significantly different $(P<0.05)$ by Tukey's multiple range test. 
range of those generally detected in methanolic extracts of Portuguese propolis (Miguel et al., 2014a).

\section{Inhibition of acetylcholinesterase}

A possible strategy for the treatment of Alzheimer's disease, which is characterised by a decline in cognitive function and mental atrophy, may include the inhibition of acetylcholinesterase, the fundamental enzyme in the breakdown of acetylcholine by the termination of the nerve impulse transmission at cholinergic synapses (Miguel et al., 2014b). Several propolis samples had similar and relatively high ability for inhibiting acetylcholinesterase: samples 1, 10, 14, 15, 16, 17, 21, 22 and 23 (Table 2). Although an inverse correlation between $\mathrm{IC}_{50}$ values and total phenols and flavonoids was observed $(P<0.01)$ (Table 3$)$, which is representative of the importance of these groups of compounds for the inhibition of acetylcholinesterase activity, sample 8 had higher concentration of phenols than sample 21, but had lower activity. According to Miguel et al. (2014b), propolis samples collected in Moulay Bousselham, Sidi Sliman, Taza, Sefrou and Kenitra were not able to inhibit acetylcholinesterase, which was in contrast to the results obtained in the present study (Table 2). The importance of phenols and flavonoids present in Moroccan propolis samples was already reported (Miguel et al., 2014b). In addition, the acetylcholinesterase inhibitory activity was also reported by Chen et al. (2008) for Chinese propolis, because water-soluble extracts, consisted of mainly flavonoids, significantly inhibited the acetylcholinesterase activity in the hippocampus of adult male Kunming mice compared to control mice given with normal saline solution. In spite of these findings by both Chen et al. (2008) and Miguel et al. (2014b), other group of compounds present in propolis samples has a role in the inhibitory activity of acetylcholinesterase, owing to the relatively good activity observed for sample 21 rather than the relatively low concentration of phenols and flavonoids.

\section{Inhibition of $\alpha$-amylase and $\alpha$-glucosidase}

Pancreatic $\alpha$-amylase is an enzyme, such as $\alpha$-glucosidase, of dietary carbohydrate digestion in humans. Inhibitors of $\alpha$-amylase may be effective in retarding carbohydrate digestion and glucose absorption and, therefore, in suppressing postprandial hyperglycaemia (Tadera et al., 2006).

$\alpha$-Glucosidase is located in the brush border surface of the intestinal cell and catalyses the final step in the

Table 2 Enzyme inhibitory activities $\left(\mathrm{IC}_{50}=\mathrm{mg} \mathrm{mL}^{-1}\right)$ of hydroalcoholic extracts of Moroccan propolis harvested at different places

\begin{tabular}{|c|c|c|c|c|c|c|}
\hline Samples & Acetylcholinesterase & $\alpha$-Amylase & $\alpha$-Glucosidase & Lipoxygenase & Tyrosinase & Xanthine oxidase \\
\hline 1 & $0.009 \pm 0.051^{\mathrm{i}}$ & $0.065 \pm 0.097^{1}$ & $0.006 \pm 0.016^{\mathrm{ef}}$ & $0.020 \pm 0.019^{n}$ & $0.050 \pm 0.192^{\mathrm{j}}$ & $0.014 \pm 0.052^{i}$ \\
\hline 2 & - & $2.020 \pm 0.097^{f}$ & - & $0.463 \pm 0.019^{\mathrm{cde}}$ & $0.374 \pm 0.192^{\mathrm{ij}}$ & $0.250 \pm 0.052^{\text {defg }}$ \\
\hline 3 & $0.535 \pm 0.051^{\mathrm{fg}}$ & $2.066 \pm 0.097^{\mathrm{ef}}$ & $0.056 \pm 0.016^{\text {cdef }}$ & $0.406 \pm 0.019^{\mathrm{efg}}$ & - & $0.245 \pm 0.052^{\text {defg }}$ \\
\hline 4 & $0.446 \pm 0.051^{\mathrm{g}}$ & $2.730 \pm 0.097^{c}$ & $0.068 \pm 0.016^{\mathrm{cd}}$ & $0.653 \pm 0.019^{a}$ & $0.971 \pm 0.192^{\mathrm{hi}}$ & $0.237 \pm 0.052^{\text {defg }}$ \\
\hline 5 & $0.199 \pm 0.051^{\mathrm{h}}$ & $3.304 \pm 0.097^{b}$ & $0.103 \pm 0.016^{\mathrm{c}}$ & $0.568 \pm 0.019^{b}$ & $3.824 \pm 0.192^{\mathrm{ab}}$ & $0.279 \pm 0.052^{\text {def }}$ \\
\hline 6 & $1.453 \pm 0.051^{c}$ & $2.417 \pm 0.097^{d}$ & $0.062 \pm 0.016^{\mathrm{cde}}$ & $0.646 \pm 0.019^{a}$ & $2.444 \pm 0.192^{d}$ & $0.585 \pm 0.052^{c}$ \\
\hline 7 & $2.034 \pm 0.051^{b}$ & $1.263 \pm 0.097^{\mathrm{hi}}$ & - & - & - & $0.753 \pm 0.052^{b}$ \\
\hline 8 & $0.188 \pm 0.051^{\mathrm{hi}}$ & $1.355 \pm 0.097^{\mathrm{hi}}$ & $0.032 \pm 0.016^{\text {def }}$ & $0.478 \pm 0.019^{\mathrm{cd}}$ & $1.595 \pm 0.192^{\mathrm{fg}}$ & $0.362 \pm 0.052^{\mathrm{de}}$ \\
\hline 9 & $0.087 \pm 0.051^{\mathrm{hi}}$ & $2.144 \pm 0.097^{\text {def }}$ & $0.027 \pm 0.016^{\mathrm{def}}$ & $0.441 \pm 0.019^{\text {def }}$ & $1.844 \pm 0.192^{e f}$ & $0.245 \pm 0.052^{\text {defg }}$ \\
\hline 10 & $0.007 \pm 0.051^{i}$ & $0.170 \pm 0.097^{1}$ & $0.007 \pm 0.016^{\mathrm{ef}}$ & $0.086 \pm 0.019^{m}$ & $0.451 \pm 0.192^{\mathrm{hij}}$ & $0.031 \pm 0.052^{i}$ \\
\hline 11 & $1.341 \pm 0.051^{c d}$ & $1.249 \pm 0.097^{\mathrm{hi}}$ & $0.018 \pm 0.016^{\text {def }}$ & $0.642 \pm 0.019^{a}$ & - & $0.179 \pm 0.052^{\mathrm{efgh}}$ \\
\hline 12 & $1.212 \pm 0.051^{d}$ & $2.853 \pm 0.097^{c}$ & - & $0.505 \pm 0.019^{c}$ & $4.286 \pm 0.192^{a}$ & $0.381 \pm 0.052^{d}$ \\
\hline 13 & $0.648 \pm 0.051^{f}$ & $3.632 \pm 0.097^{a}$ & $0.746 \pm 0.016^{a}$ & $0.372 \pm 0.019^{g h}$ & - & $0.162 \pm 0.052^{f g h}$ \\
\hline 14 & $0.002 \pm 0.051^{i}$ & $0.855 \pm 0.097^{\mathrm{j}}$ & $0.019 \pm 0.016^{\text {def }}$ & $0.239 \pm 0.019^{k}$ & $0.295 \pm 0.192^{\mathrm{j}}$ & $0.219 \pm 0.052^{\text {defg }}$ \\
\hline 15 & $0.024 \pm 0.051^{i}$ & $1.484 \pm 0.097^{\mathrm{gh}}$ & $0.027 \pm 0.016^{\text {def }}$ & $0.152 \pm 0.019^{1}$ & $0.612 \pm 0.192^{h i j}$ & $0.076 \pm 0.052^{h i}$ \\
\hline 16 & $0.007 \pm 0.051^{i}$ & $1.450 \pm 0.097^{g h}$ & $0.025 \pm 0.016^{\text {def }}$ & $0.256 \pm 0.019^{j k}$ & $3.600 \pm 0.192^{b c}$ & $0.125 \pm 0.052^{\mathrm{fgh}}$ \\
\hline 17 & $0.003 \pm 0.051^{i}$ & $0.146 \pm 0.097^{1}$ & $0.014 \pm 0.016^{\text {def }}$ & $0.065 \pm 0.019^{\mathrm{mn}}$ & $0.110 \pm 0.192^{\mathrm{j}}$ & $0.017 \pm 0.052^{i}$ \\
\hline 18 & $0.123 \pm 0.051^{\mathrm{hi}}$ & $2.338 \pm 0.097^{\mathrm{de}}$ & $0.155 \pm 0.016^{b}$ & $0.574 \pm 0.019^{b}$ & - & $0.619 \pm 0.052^{b c}$ \\
\hline 19 & $0.871 \pm 0.051^{\mathrm{e}}$ & $0.524 \pm 0.097^{\mathrm{k}}$ & $0.176 \pm 0.016^{\mathrm{b}}$ & $0.324 \pm 0.019^{h i}$ & $2.288 \pm 0.192^{\mathrm{de}}$ & $0.279 \pm 0.052^{\text {def }}$ \\
\hline 20 & $0.160 \pm 0.051^{\mathrm{hi}}$ & $0.493 \pm 0.097^{\mathrm{k}}$ & $0.015 \pm 0.016^{\text {def }}$ & $0.312 \pm 0.019_{\mathrm{ij}}$ & $1.047 \pm 0.192^{\mathrm{gh}}$ & $0.279 \pm 0.052^{\text {def }}$ \\
\hline 21 & $0.009 \pm 0.051^{i}$ & $3.471 \pm 0.097^{a b}$ & - & $0.425 \pm 0.019^{\text {defg }}$ & - & $3.116 \pm 0.052^{a}$ \\
\hline 22 & $0.013 \pm 0.051^{i}$ & $1.080 \pm 0.097^{\mathrm{ij}}$ & $0.038 \pm 0.016^{\text {def }}$ & $0.253 \pm 0.019^{\mathrm{jk}}$ & $3.173 \pm 0.192^{\mathrm{c}}$ & $0.252 \pm 0.052^{\text {defg }}$ \\
\hline 23 & $0.013 \pm 0.051^{i}$ & $0.018 \pm 0.097^{1}$ & $0.002 \pm 0.016^{f}$ & $0.046 \pm 0.019^{\mathrm{mn}}$ & $0.037 \pm 0.192^{j}$ & $0.008 \pm 0.052^{i}$ \\
\hline 24 & $3.555 \pm 0.051^{a}$ & $1.692 \pm 0.097^{\mathrm{g}}$ & - & $0.393 \pm 0.019^{f g}$ & - & $0.391 \pm 0.052^{d}$ \\
\hline
\end{tabular}

-: without activity.

Values in the same column followed by the same letter are not significantly different $(P<0.05)$ by Tukey's multiple range test. 


\begin{tabular}{lccc}
\hline & Total phenol & Flavone + Flavonol & $\begin{array}{c}\text { Flavanone }+ \\
\text { Dihydroflavonol }\end{array}$ \\
\hline Total phenol & 1 & $0.965^{* *}$ & $0.858^{* *}$ \\
Flavone + Flavonol & $0.965^{* *}$ & 1 & $0.850^{* *}$ \\
Flavanone + Dihydroflavonol & $0.858^{* *}$ & $0.850^{* *}$ & 1 \\
Acetylcholinesterase & $-0.638^{* *}$ & $-0.648^{* *}$ & $-0.750^{* *}$ \\
$\alpha$-Amylase & $-0.663^{* *}$ & $-0.653^{* *}$ & $-0.631^{* *}$ \\
$\alpha$-Glucosidase & $-0.729^{* *}$ & $-0.663^{* *}$ & $-0.687^{* *}$ \\
Lipoxygenase & $-0.714^{* *}$ & $-0.697^{* *}$ & $-0.863^{* *}$ \\
Tyrosinase & $-0.698^{* *}$ & $-0.634^{* *}$ & $-0.568^{*}$ \\
Xanthine oxidase & $-0.718^{* *}$ & $-0.666^{* *}$ & $-0.674^{* *}$ \\
\hline
\end{tabular}

Table 3 Spearman's correlation coefficients between total phenols and flavonoids and enzyme inhibitory activities digestive process of carbohydrates, releasing absorbable monosaccharides. This process is responsible for the increased blood glucose levels (Zhang et al., 2015). When that enzyme is inhibited, the liberation of D-glucose from dietary complex carbohydrates can be retarded and may delay the digestion and absorption of carbohydrates and restrain postprandial hyperglycaemic episode (Zhang et al., 2015).

Concerning $\alpha$-amylase, samples 1 and 23 had the lowest $\mathrm{IC}_{50}$ values $\left(0.065\right.$ and $0.018 \mathrm{mg} \mathrm{mL}^{-1}$, respectively), although not significantly different to those found for samples 10 and $17 \quad(0.17$ and $0.146 \mathrm{mg} \mathrm{mL}^{-1}$, respectively) (Table 2). Such as observed for $\alpha$-glucosidase, the $\alpha$-amylase inhibitor activity of propolis extracts, expressed as $\mathrm{IC}_{50}$ values, is inversely correlated with total phenols and flavonoid concentrations $(P<0.01) \quad$ (Table 3$)$. Caffeoylquinic acid derivatives as well as flavonoids from Brazilian propolis have been reported as being able to inhibit both $\alpha$-glucosidase and $\alpha$-amylase activities and, therefore, with hypoglycaemic property (Matsui et al., 2004; Tadera et al., 2006).

Sample 23 (geographical origin unknown) was the best inhibitor of $\alpha$-glucosidase $\left(\mathrm{IC}_{50}=0.002 \mathrm{mg} \mathrm{mL}^{-1}\right)$, immediately followed by the samples 1 (Sefrou) and 10 (geographical origin unknown) $\left(\mathrm{IC}_{50}=0.006\right.$ and $0.007 \mathrm{mg} \mathrm{mL}^{-1}$, respectively) (Table 2). Such as reported for the inhibitory activities reported above, also in this case, the activity was inversely correlated with the amounts of total phenols and flavonoids (Table 3). The inhibitory activity of propolis extracts against $\alpha$-glucosidase was already reported in other propolis extracts of different geographical origins (Zhang et al., 2015; Popova et al., 2015). Although two samples of propolis studied by Popova et al. (2015) were from the same city of those reported in the present work (2 and 9: Moulay Bousselhame; 8: Rabat), their activities were different. For the sample from Moulay Bousselham, the inhibitory activities, expressed as $\mathrm{IC}_{50}$ values, of $\alpha$-glucosidase and $\alpha$-amylase were 0.07 and $0.52 \mathrm{mg} \mathrm{mL}^{-1}$, respectively, while in the present work such $\mathrm{IC}_{50}$ values for $\alpha$-glucosidase inhibitory activities ranged from without activity (sample 2) up to $0.027 \mathrm{mg} \mathrm{mL}^{-1}$ (sample 9). Concerning $\alpha$-amylase inhibitory activities, $\mathrm{IC}_{50}$ values were 2.0-2.1 $\mathrm{mg} \mathrm{mL}^{-1}$ for samples 2 and 9, respectively. For the sample from Rabat, Popova et al. (2015) found 0.010 and $0.090 \mathrm{mg} \mathrm{mL}^{-1}$ as $\mathrm{IC}_{50}$ values for $\alpha$-glucosidase and $\alpha$-amylase inhibitory activities, respectively, that is lower than those observed for sample $8\left(0.032\right.$ and $\left.1.36 \mathrm{mg} \mathrm{mL}^{-1}\right)$ (Table 2).

The lowest $\mathrm{IC}_{50}$ values found in the present work are similar to those reported by Zhang et al. (2015), for aqueous ethanol extracts of Brazilian propolis. The hypoglycaemic activity of propolis when mixed with mulberry leaf extract was already reported by Murata et al. (2004) after the administration to patients with type 2 diabetes.

\section{Inhibition of lipoxygenase}

After the oxidation of arachidonic acid, 5-lipoxygenase is responsible for the formation of the proinflammatory leukotrienes. Linoleic acid is also a substrate for this enzyme, which is enzymatically converted by 5-lipoxygenase to a conjugated diene, which results in a continuous increase in absorbance at $234 \mathrm{~nm}$ (Miguel et al., 2011).

Sample 1 had the lowest $\mathrm{IC}_{50}$ value $\left(0.020 \mathrm{mg} \mathrm{mL}^{-1}\right)$ - so that it had the ability to inhibit 5-lipoxygenase - immediately followed by the sample 17 and sample $23\left(\mathrm{IC}_{50}=0.065\right.$ and $0.046 \mathrm{mg} \mathrm{mL}^{-1}$, respectively) (Table 2). These values are significantly lower than those previously reported by Miguel et al. (2014b) for Moroccan propolis extracts from different origins. Although the samples possess the same harvesting place (Moulay Bousselham, Rabat, Sidi Sliman, Taza, Sefrou and Kenitra) as the samples investigated by Miguel et al. (2014b), only that from Rabat had higher $\mathrm{IC}_{50}$ value. A negative correlation was observed between the $\mathrm{IC}_{50}$ values and the concentration of total phenols and flavonoids (Table 3), 
particularly flavanones and dihydroflavonols. This type of correlation was already reported for Moroccan propolis (Miguel et al., 2014b).

Mirzoeva \& Calder (1996) found that propolis and its components caffeic acid phenethyl ester (CAPE), caffeic acid (CA), quercetin and naringenin significantly suppressed the lipoxygenase pathway of arachidonic acid metabolism during inflammation in vivo. However, CAPE was the most potent modulator of the arachidonic acid metabolism among the propolis components studied by the authors. However, according to Araújo et al. (2012), the anti-inflammatory activity of propolis seems to be particularly associated with the presence of flavonoids, especially galangin and quercetin. These flavonoids have been shown to inhibit the activity of lipoxygenase, among other enzymes and factors responsible for inflammation processes: inhibition of cyclooxygenase, reduction in the levels of $\mathrm{PGE}_{2}$ as well as in the release and expression of the induced isoform cyclooxygenase-2 (COX-2). In the present work, the compounds were not identified; nevertheless, the correlation between the inhibitory activity and flavanones and dihydroflavonol contents was strong compared to the remaining correlations between phenol content and inhibitory activity, which may suppose to have higher importance of those kinds of compounds in the lipoxygenase inhibitory activity.

\section{Inhibition of tyrosinase}

The tyrosinase inhibition by propolis samples is depicted in Table 2. Samples 1 and 23 were the most active against this enzyme, with $\mathrm{IC}_{50}$ values of 0.050 and $0.037 \mathrm{mg} \mathrm{mL}^{-1}$, respectively. These values were not significantly different (Table 2). An inverse correlation was observed between the inhibition activity presented as $\mathrm{IC}_{50}$ values and the concentrations of total phenols and flavonoids, demonstrating that these compounds have an important role in the inhibition of tyrosinase (Table 3). Some flavonoids have demonstrated to be able to inhibit mushroom tyrosinase by the chelation of active sites. Examples include the chelation reactions between the vicinal $3^{\prime}, 4^{\prime}$-dihydroxyl group of catechin and the $\mathrm{Cu}^{2+}$ on tyrosinase, or still the structure of 3hydroxy-4-keto moiety in some flavonoids, such as quercetin (Fu et al., 2005). Other studies revealed that caffeic acid phenethyl ester suppresses melanogenic enzyme expression, but not via a direct inhibition of tyrosinase activity itself (Lee et al., 2013).

\section{Inhibition of xanthine oxidase}

The inhibitory activity expressed as $\mathrm{IC}_{50}$ values is presented in Table 2. Without significant differences $(P<0.05)$, the propolis samples $1,10,17$ and 23 possessed the lowest $\mathrm{IC}_{50}$ values $(0.014,0.031,0.017$ and
$0.008 \mathrm{mg} \mathrm{mL}^{-1}$, respectively) and therefore are considered as the best ones for inhibiting xanthine oxidase activity (Table 2). As reported for the other inhibitory enzyme activities, there was an inverse correlation between $\mathrm{IC}_{50}$ values and the amounts of phenols and flavonoids (Table 3). According to Cos et al. (1998), flavonoids possess the capacity for inhibiting xanthine oxidase - mainly those showing the hydroxyl groups at C-5 and C-7 and the double bond between C-2 and $\mathrm{C}-3-$ and found that the presence of a hydroxyl group at C-3 would slightly decrease the inhibitory activity. Yoshizumi et al. (2005) reported that propolis from China with relatively high amounts of chrysin, galangin and caffeic acid phenethyl ester possessed higher inhibitory activity than the Brazilian propolis with higher amounts of $p$-coumaric acid and artepillin $\mathrm{C}$ and also concluded that a continuous intake of propolis could be effective for the prevention and the treatment of gout and hyperuricaemia.

\section{Inhibition of hyaluronidase}

Figure 1 presents the percentage of inhibition of hyaluronidase obtained from Moroccan propolis extracts when at a final concentration of $33.33 \mathrm{mg} \mathrm{mL}^{-1}$. Samples $1,8,10,14,17,20$ and 22 had percentages of inhibition higher than $80 \%$, whereas the samples 7,12 and 21 even at those relatively high concentrations $\left(33.33 \mathrm{mg} \mathrm{mL} \mathrm{m}^{-1}\right)$ did not present the ability for inhibiting the hyaluronidase enzyme.

The capacity of Portuguese propolis extracts for inhibiting hyaluronidase was already reported (Silva et al., 2012). The values found by these authors were also dependent on the place of harvesting, such as observed by us in the present work. Silva et al. (2012) did not find a correlation between phenol contents and activity, suggesting that other components present in the propolis extracts, such as proteins and vitamins, might also be involved in the activity.

\section{Statistical analysis}

A combination of cluster analysis using Ward's technique (Fig. 2a) revealed the presence of three principal clusters with respect to the phenol, flavone, flavonol, flavanone, dihydroflavonol content, $\alpha$-amylase and xanthine oxidase inhibitory activities of 24 samples. Samples belonging to cluster 1 included propolis sample 1 (region Fez-Boulemane), 10 (purchased from the market), 17 (region Fez-Boulemane) and 23 (purchased from the market). These samples had the highest concentration of all types of phenols as well as the highest inhibitory activities of xanthine oxidase and $\alpha$-amylase. Cluster 2 included samples 2-7, 9, 11$13,18,19,21$ and 24 , which possessed the lowest activities as well as the lowest amounts of all types of 
phenols. The harvesting places for these propolis samples are widespread all over the country. Samples 8 (region Rabat), 14 (region Gharb), 15 (region Rabat), 16 (region Gharb), 20 and 22 (both from Fez-Boulemane) possessed intermediate concentrations of phenols and inhibitory activities. Some of these samples (14 and 16) were collected in regions of Gharb in which other samples were also harvested and had lower amounts of phenols and lower activities (samples 9 and 13 from cluster 2) and therefore belonged to the cluster 2. Samples in cluster 3 (samples 20 and 22, which were harvested in Fez-Boulemane region) and the samples 1 and 17 in cluster 1 had the best inhibitory activities as well as the highest phenol content (Tables 1 and 2).

Three principal clusters with respect to the phenol, flavone, flavonol, flavanone, dihydroflavonol contents and $\alpha$-glucosidase, lipoxygenase, acetylcholinesterase and tyrosinase inhibitory activities (Fig. 2b) were found for 15 samples. Samples 1, 10, 17 and 23 belonged to cluster 1 ; samples $4-6,9,15,19$ and 22 belonged to cluster 2; and samples 8, 14, 16 and 20 belonged to cluster 3 . The distribution of samples by clusters was the same as that of reported above. A drawback of the present work is the limited number of samples, which makes it difficult to draw conclusions; nevertheless, it is possible to find propolis samples in the same region having dissimilar phenol contents and enzyme inhibitory activities. In addition, great part of samples had relatively small amounts of phenols and consequently weak enzyme inhibitory activities. In this way, the activities correlated well with the phenol content, but in the same region, it was possible to find the samples with dissimilar properties.

\section{Conclusions}

Propolis samples from different places of Morocco had diverse amounts of total phenols, flavones, flavonols, flavanones and dihydroflavonols. Those samples with higher concentrations of these groups of compounds generally had the best capacity to inhibit the activities of acetylcholinesterase, $\alpha$-amylase and $\alpha$-glucosidase, lipoxygenase, tyrosinase, xanthine oxidase and hyaluronidase. A correlation between harvesting place of propolis samples and phenol content or inhibitory enzyme activities was not found in the present work, because in the same place, samples with dissimilar phenol contents and enzyme activities were found. In addition, dissimilar activities and phenol contents were also found in the three propolis samples purchased from the market, which in turn reveals the importance of normalisation of these natural products because propolis sold in the market shows distinct efficacious activities, not consistent with the requirements of quality, efficiency and safety that these products should have.

Even in the absence of a deep chemical characterisation of samples, it was possible to conclude the importance of polyphenols in inhibiting enzyme activities given the correlations found between polyphenol contents and activities. For the inhibitory activity of the enzymes studied in the present work, the results may suggest that a phenol normalisation of the extracts may be enough, without the need for chemically characterising them. Such results must be the target of further study for deeply evaluating the possibility to use these products in the combat of some diseases involving inflammation, hyperuricaemia or gout,

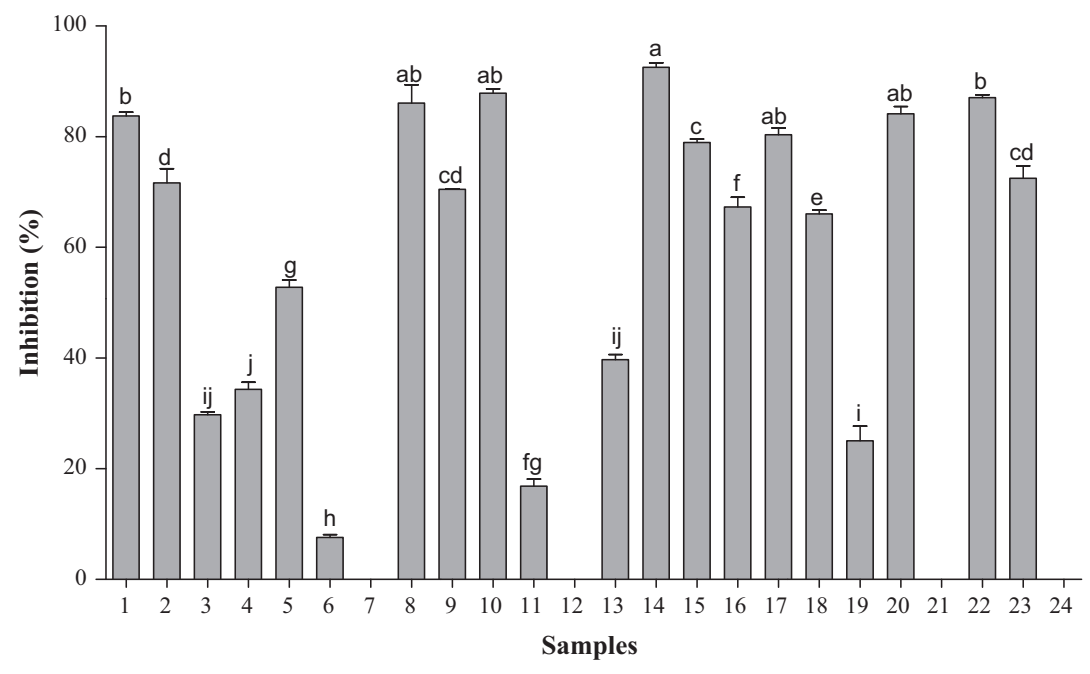

International Journal of Food Science and Technology 2016
Figure 1 Percentage of hyaluronidase inhibition obtained from propolis extracts (33.33 $\mathrm{mg} \mathrm{mL}^{-1}$ ) collected at different places of morocco. Bars represent standard deviations $(n=3)$. In many cases, such bars may not be visible due to the very low standard deviations. Values with the same letter are not significantly different $(P<0.05)$ by Tukey's multiple range test. 
Figure 2 (a) Dendrogram obtained from the cluster analysis of 24 samples of propolis from Morocco with respect to the total phenols, flavones and flavonols, flavanones and dihydroflavonols contents and the capacity to inhibit xanthine oxidase and $\alpha$-amylase. Samples were clustered using Ward's technique with the squared Euclidean distance measure. (b) Dendrogram obtained from the cluster analysis of 15 samples of propolis from Morocco with respect to the total phenols, flavones and flavonols, flavanones and dihydroflavonols contents and the capacity to inhibit acetylcholinesterase, $\alpha$-glucosidase, lipoxygenase and tyrosinase. Samples were clustered using Ward's technique with the squared Euclidean distance measure.
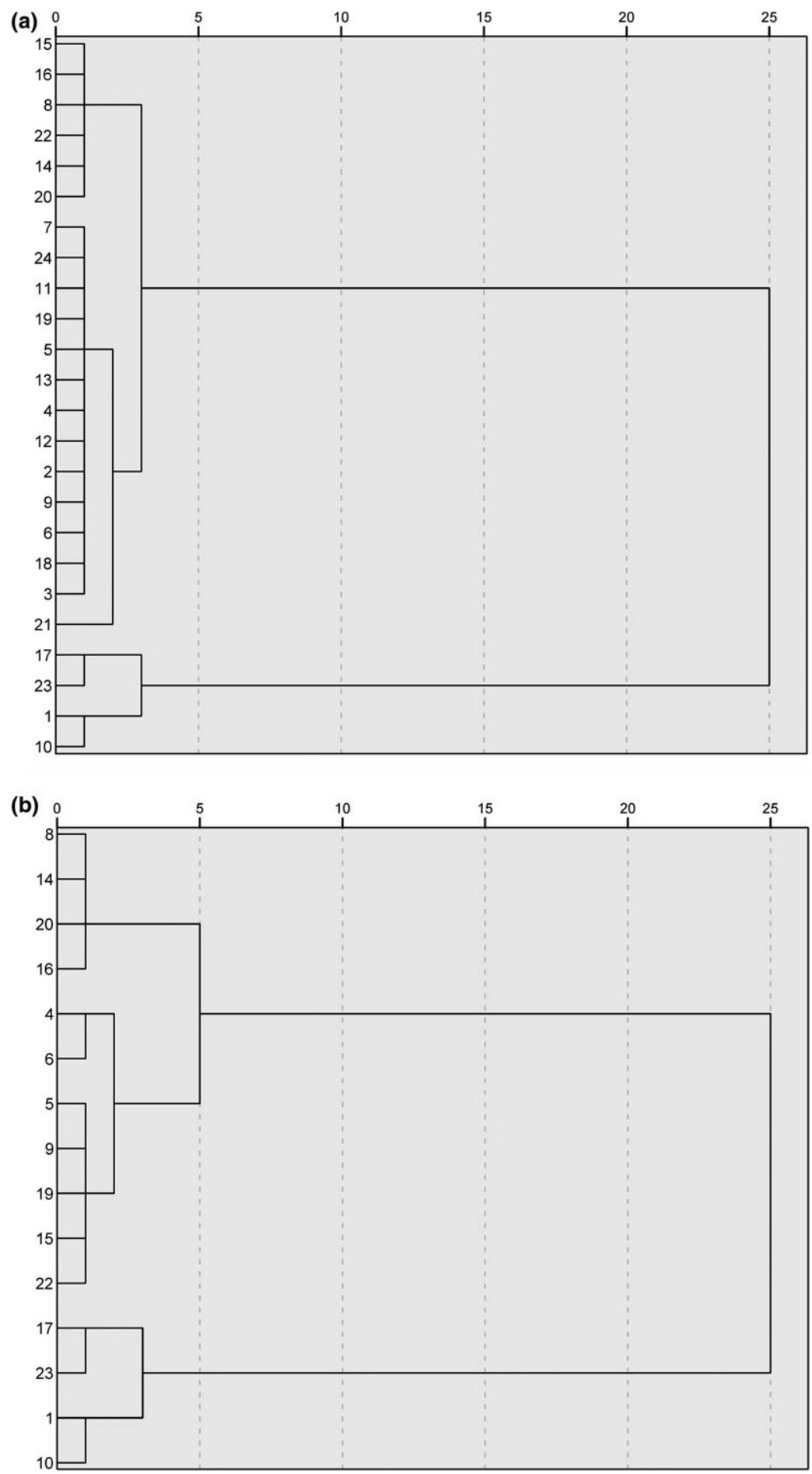

hyperglycaemia, in those diseases characterised by a decline in cognitive function and mental atrophy, or as agents still for the treatment of hyperpigmentation of the human skin.

\section{Acknowledgments}

The authors are grateful to FCT - Fundação para a Ciência e Tecnologia (PEst-OE/EQB/LA0023/2013). 


\section{Conflict of interest}

The authors declare no conflict of interests.

\section{References}

Araújo, M.A.R., Libério, S.A., Guerra, R.N.M., Ribeiro, M.N.S. \& Nascimento, F.R.F. (2012). Mechanisms of action underlying the anti-inflammatory and immunomodulatory effects of propolis: a brief review. Brazilian Journal of Pharmacognosy, 22, 208-219.

Armutcu, F., Akyol, S., Ustunsoy, S. \& Turan, F.F. (2015). Therapeutical potential of caffeic acid phenethyl ester and its anti-inflammatory and immunomodulatory effects (review). Experimental and Therapeutic Medicine, 9, 1582-1588.

Boufadi, Y.M., Soubhye, J., Riazi, A., Rousseau, A. et al. (2014). Characterization and antioxidant properties of six Algerian propolis extracts: ethyl acetate extracts inhibit myeloperoxidase activity. International Journal of Molecular Science, 15, 2327-2345.

Chen, J., Long, Y., Han, M., Wang, T., Chen, Q. \& Wang, R. (2008). Water-soluble derivative of propolis mitigates scopolamineinduced learning and memory impairment in mice. Pharmacology, Biochemistry and Behavior, 90, 441-446.

Cos, P., Ying, L., Calomme, M. et al. (1998). Structure-activity relationship and classification of flavonoids as inhibitors of xanthine oxidase and superoxide scavengers. Journal of Natural Products, 61, 71-76.

Dong, Y., Zhao, M., Zhao, T. et al. (2014). Bioactive profiles, antioxidant activities, nitrite scavenging capacities and protective effects on $\mathrm{H}_{2} \mathrm{O}_{2}$-injured PC12 cells of Glycyrrhiza glabra L. leaf and root extracts. Molecules, 19, 9101-9113.

El-Hady, F.K.A., Abdel-Aziz, M.S., Shaker, K.H. \& El-Shahid, Z.A. (2014). Tyrosinase, acetylcholinesterase inhibitory potential, antioxidant and antimicrobial activities of sponge derived fungi with correlation to their GC/MS analysis. International Journal of Pharmaceutical Sciences Review and Research, 26, 338-345.

Frum, Y. \& Viljoen, A.M. (2006). In vitro 5-lipoxygenase activity of three indigenous South African aromatic plants used in traditional healing and the stereospecific activity of limonene in the 5-lipoxygenase assay. Journal of Essential Oil Research, 18, 85-88.

Fu, B., Li, H., Wang, X., Lee, F.S.C. \& Cui, S. (2005). Isolation and identification of flavonoids in licorice and a study of their inhibitory effects on tyrosinase. Journal of Agricultural and Food Chemistry, 53, 7408-7414.

Gülcin, I., Beydemir, S., Sat, I.G. \& Kufreviogl, O.I. (2005). Evaluation of antioxidant activity of cornelian cherry (Cornus mas L.). Acta Alimentaria Hungarica, 34, 193-202.

Ilhan, A., Akyol, O., Gurel, A., Armutcu, F., Iraz, M. \& Oztas, E. (2004). Protective effects of caffeic acid phenethyl ester against experimental allergic encephalomyelitis-induced oxidative stress in rats. Free Radical Biology \& Medicine, 37, 386-394.

Kang, S.Y., Lee, K.Y., Koo, K.A. et al. (2005). ESP-102, a standardized combined extract of Angelica gigas, Saururus chinensis and Schizandra chinensis, significantly improved scopolamineinduced memory impairment in mice. Life Sciences, 76, 1691-1705.

Lee, J.-Y., Choi, H.-J., Chung, T.-W., Kim, C.-H., Jeong, H.-S. \& Ha, K.-T. (2013). Caffeic acid phenethyl ester inhibits alpha-melanocyte stimulating hormone-induced melanin synthesis through suppressing transactivation activity of microphthalmia-associated transcription factor. Journal of Natural Products, 76, 1399-1405.

Mata, A.T., Proença, C., Ferreira, A.R., Serralheiro, M.L.M., Nogueira, J.M.F. \& Araújo, M.E.M. (2007). Antioxidant and antiacetylcholinesterase activities of five plants used as Portuguese food spices. Food Chemistry, 103, 778-786.

Matsui, T., Ebuchi, S., Fujise, T. et al. (2004). Strong antihyperglycemic effects of water-soluble fraction of Brazilian propolis and its bioactive constituent 3,4,5-tri-O-caffeoylquinic acid. Biological and Pharmaceutical Bulletin, 27, 1797-1803.
Miguel, M.G., Nunes, S., Dandlen, S.A., Cavaco, A.M. \& Antunes, M.D. (2010). Phenols and antioxidant activities of hydro-alcoholic extracts of propolis from Algarve, South of Portugal. Food and Chemical Toxicology, 48, 3418-3423.

Miguel, M.G., Cruz, C., Faleiro, M.L. et al. (2011). Salvia officinalis L. essential oils: effect of hydrodistillation, time on the chemical composition, antioxidant and antimicrobial activities. Natural Product Research, 25, 526-541.

Miguel, M.G., Nunes, S., Dandlen, S.A., Cavaco, A.M. \& Antunes, M.D. (2014a). Phenols, flavonoids and antioxidant activity of aqueous and methanolic extracts of propolis (Apis mellifera L.) from Algarve, South Portugal. Food Science and Technology (Campinas), 34, 16-23.

Miguel, M.G., Doughmi, O., Aazza, S., Antunes, D. \& Lyoussi, B. (2014b). Antioxidant, anti-inflammatory and acetylcholinesterase inhibitory activities of propolis from different regions of Morocco. Food Science Biotechnology, 23, 313-322.

Mirzoeva, O.K. \& Calder, P.C. (1996). The effect of propolis and its components on eicosanoid production during the inflammatory response. Prostaglandins, Leukotrienes and Essential Fatty Acids, 55, 441-449.

Miyataka, H., Nishiki, M., Matsumoto, H., Fujimoto, T., Matsuka, M. \& Satoh, T. (1997). Evaluation of propolis. 1. Evaluation of Brazilian and Chinese propolis by enzymatic and physico-chemical methods. Biological and Pharmaceutical Bulletin, 20, 496-501.

Moon, S.-H., Kim, K.-T., Lee, N.-K. et al. (2009). Inhibitory effects of naringenin and its novel derivatives on hyaluronidase. Food Science Biotechnology, 18, 267-270.

Mouse, H.A., Tilaoui, M., Jaafari, A. et al. (2012). Evaluation of the in vitro and in vivo anticancer properties of Moroccan propolis extracts. Brazilian Journal of Pharmacognosy, 22, 558-567.

Murai, A., Iwamura, K., Takada, M., Ogawa, K., Usui, T. \& Okumura, J.-I. (2002). Control of postprandial hyperglycaemia by galactosylmaltobionolactone and its novel anti-amylase effect in mice. Life Sciences, 71, 1405-1415.

Murata, K., Yatsunami, K., Fukuda, E. et al. (2004). Antihyperglycemic effects of propolis mixed with mulberry leaf extract to patients with type 2 diabetes. Alternative Therapies, 10, 78-79.

Nerya, O., Vaya, J., Musa, R., Izrael, S., Ben-Artie, R. \& Tamir, S. (2003). Glabrene and isoliquiritigenin as tyrosinase inhibitors from licorice roots. Journal of Agricultural and Food Chemistry, 51, 1201-1207.

Park, Y.K. \& Ikegaki, M. (1998). Preparation of water and ethanolic extracts of propolis and evaluation of the preparations. Bioscience, Biotechnology, and Biochemistry, 62, 2230-2232.

Popova, M., Bankova, V., Butovska, D. et al. (2004). Validated methods for the quantification of biologically active constituents of Poplar-type propolis. Phytochemical Analysis, 15, 235-240.

Popova, M., Lyoussi, B., Aazza, S., Bankova, V. \& Miguel, G. (2015). Antioxidant and $\alpha$-glucosidase inhibitory properties and chemical profiles of Moroccan propolis. Natural Product Communications, 10, 1961-1964.

Sahasrabudhe, A. \& Deodhar, M. (2010). Anti-hyaluronidase, antielastase activity of Garcinia indica. International Journal of Botany, 6, 299-303.

Sailer, E.-R., Subramanian, L.R., Rall, B., Hoernhein, R.F., Ammon, H.P.T. \& Safayhi, H. (1996). Acetyl-11-keto- $\beta$-boswellic acid (AKBA): structure requirements for binding and 5-lipoxygenase inhibitory activity. British Journal of Pharmacology, 117, 615-618.

Salatino, A., Fernandes-Silva, C.C., Righi, A.A. \& Salatino, M.L.F. (2011). Propolis research and the chemistry of plant products. Natural Product Reports, 28, 925-936.

Scotti, L. \& Scotti, M.T. (2015). Computer aided drug design studies in the discovery of secondary metabolites targeted against agerelated neurodegenerative diseases. Current Topics in Medicinal Chemistry, 15, 2239-2252. 
Huang, S., Zhang, C.-P., Wang, K., Li, G.Q., \& Hu, F.-L. (2014). Recent advances in the chemical composition of propolis. Molecules, 19, 19610-19632.

Silici, S. \& Kutluca, S. (2005). Chemical composition and antibacterial activity of propolis collected by three different races of honeybees in the same region. Journal of Ethnopharmacology, 99, 69-773.

Silva, J.C., Rodrigues, S., Feás, X. \& Estevinho, L.M. (2012). Antimicrobial activity, phenolic profile and role in the inflammation of propolis. Food and Chemical Toxicology, 50, 1790-1795.

Silva-Carvalho, R., Baltazar, F. \& Almeida-Aguiar, C. (2015). Propolis: a complex natural product with a plethora of biological activities that can be explored for drug development. EvidenceBased Complementary and Alternative Medicine, Article ID 206439, 29 pages. [Online] Available at: http://dx.doi.org/10.1155/2015/ 206439. Accessed on 17 August 2015

Sud'ina, G.F., Mirzoeva, O.K., Pushkareva, M.A., Korshunova, G.A., Sumbatyan, N.V. \& Varfolomeev, S.D. (1993). Caffeic acid phenethyl ester as a lipoxygenase inhibitor with antioxidant properties. FEBS Letters, 329, 21-24.

Tadera, K., Minami, Y., Takamatsu, K. \& Matsuoka, T. (2006). Inhibition of $\alpha$-glucosidase and $\alpha$-amylase by flavonoids. Journal of Nutritional Science and Vitaminology, 52, 149-152.

Tazawa, S., Warashina, T. \& Noro, T. (2001). Tyrosinase inhibitors of Brazilian propolis. Natural Medicines, 55, 111-118.

Touaibia, M. \& Guay, M. (2011). Natural product total synthesis in the organic laboratory: total synthesis of caffeic acid and phenethyl ester (CAPE), a potent 5-lipoxygenase inhibitor from honeybee hives. Journal of Chemical Society, 88, 473-745.
Uddin, N., Hasan, M.R., Hossain, M.M. et al. (2014). In vitro $\alpha$ amylase inhibitory activity and in vivo hypoglycemic effect of methanol extract of Citrus macroptera Montr. fruit. Asian Pacific Journal of Tropical Biomedicine, 4, 473-479.

Umamaheswari, M., Madeswaran, A. \& Asokkumar, K. (2013). Virtual Screening Analysis and in-vitro xanthine oxidase inhibitory activity of some commercially available flavonoids, Iran. Journal of Pharmacy Research, 12, 317-323.

Yoshizumi, K., Nishioka, N. \& Tsuje, T. (2005). The xanthine oxidase inhibitory activity and hypouricemic effect of the propolis in rats. Yakugaku Zasshi - Journal of the Pharmaceutical Society of Japan, 125, 315-321 (Japanese).

Zhang, H., Wang, G., Beta, T. \& Dong, J. (2015). Inhibitory properties of aqueous ethanol extracts of propolis on alpha-glucosidase. Evidence-Based Complementary and Alternative Medicine, Article ID 587383, 7 pages. [Online] Available at: http://dx.doi.org/ 10.1155/2015/587383. Accessed on 17 August 2015.

\section{Supporting Information}

Additional Supporting Information may be found in the online version of this article:

Table S1. Harvesting places of Moroccan propolis and their coordinates as well the surrounding plants. 